\title{
COMPARING SURFACE WETNESS INSIDE AND OUTSIDE GRAPE CANOPIES FOR REGION-WIDE ASSESSMENT OF PLANT DISEASE RISK
}

\author{
W.R. HENSHALL, R.M. BERESFORD, R.W. CHYNOWETH \\ and P. RAMANKUTTY
}

HortResearch, Private Bag 92169, Auckland, New Zealand

Corresponding author: whenshall@hortresearch.co.nz.

\begin{abstract}
Wetness duration measured by flat plate sensors inside and outside a grape canopy was recorded from December-March. Sensors outside the canopy generally recorded longer wetness duration than sensors inside the canopy. For days with rain, short wetness durations detected by outside sensors were not detected by inside sensors because of sheltering by the canopy. When wetness arose solely from dew, duration inside was much shorter than outside for prolonged wet periods. Wetness was used to calculate infection periods according to two botrytis bunch rot risk models. Agreement between sensors was worse inside the canopy than outside, although on occasions when rainfall exceeded $10 \mathrm{~mm}$ there was greater uniformity between sensors. For region-wide disease risk monitoring, wetness duration measured outside leaf canopies at standard meteorological sites would give a "worst-case" estimate of disease risk. Regression equations are presented that allow estimation of inside wetness duration from outside wetness duration for rainy and non-rainy days.

Keywords: wetness sensor, grape, botrytis bunch rot, disease model.
\end{abstract}

\section{INTRODUCTION}

Surface wetness duration, measured with electrical impedance grids (Gillespie \& Kidd 1978), is an important input variable for weather-driven plant disease forecasting models. Such models have generally been implemented using wetness data from discrete weather stations within a region (e.g. Agnew et al. 2004). Improvement in region-wide assessment of disease risk should be possible by spatial interpolation of wetness duration between stations, taking into account a range of micro- and meso-scale factors. One important factor affecting wetness duration is the crop leaf canopy.

In a previous study variability between 25 wetness sensors in a grape canopy arranged in five groups of five sensors at $2 \mathrm{~m}$ spacings was investigated (Henshall et al. 2003). Few botrytis bunch rot (Botrytis cinerea) infection periods (IPs) based on wetness duration (Broome et al. 1995) were common to all sensors. As further analysis found instantaneous wetness sensor outputs were uncorrelated at the $2 \mathrm{~m}$ spacing it was decided to conduct a further study with closer sensor spacing and with sensors both outside and inside the canopy. This study compared wetness duration inside and outside a grape leaf canopy over four months of the grape growing season in New Zealand and compared IPs calculated from inside and outside wetness sensors.

\section{METHODS}

Ten unpainted flat plate wetness sensors (Campbell Scientific type 237) were set up over grass next to a weather station at Pukekohe, Franklin District. They were arranged as five pairs of sensors, with the pairs spaced $0.5 \mathrm{~m}$ apart in a line. A further five pairs at $0.5 \mathrm{~m}$ spacings were similarly arranged within an adjacent grape canopy. The canopy was cv. Sauvignon Blanc and was trained as vertically positioned shoots 
on a narrow fence with leaf removal and shoot trimming occurring on two occasions during the season. All sensors were $0.8 \mathrm{~m}$ above ground, approximately at the level of grape bunches. The sensors provided outputs ranging from 0 to 100, with readings $>50$ considered wet. Sensor outputs were scanned every $60 \mathrm{~s}$ and the means logged every $15 \mathrm{~min}$, from mid-December 2002 to the end of March 2003. The number of 15-min intervals recorded wet per day (midnight to midnight) was calculated for each sensor, and converted to number of hours wet per day, for rainy days (rain $>0 \mathrm{~mm}$ ) and nonrainy days (rain $=0 \mathrm{~mm}$ ). Separate comparisons were made for individual months and over all months combined.

The relationship between surface wetness duration inside the grape canopy and that outside the canopy was investigate by fitting the following model to the data using GenStat Release 8.1 for Windows XP:

$$
\mathrm{y}=\mu+\alpha \mathrm{x}_{1}+\beta \mathrm{x}_{2}+\gamma \mathrm{x}_{1} \mathrm{x}_{2}+\varepsilon
$$

where $y$ is the average hours of wetness measured inside the canopy, $x_{1}$ is the average hours of wetness measured outside the canopy, $\mathrm{x}_{2}$ is a variable characterising whether the day is rainy or not ( 0 if non-rainy, 1 if rainy) and $\varepsilon$ is the error term. It was assumed that the error terms were normally and independently distributed with zero mean and constant variances. Examination of histogram, normal probability and scatter plots of the residuals showed no evidence of violation of these assumptions.

The variance of the number of hours wet per day measured outside the canopy was compared with that measured inside the canopy using the F-ratio. In addition, data for each sensor were aggregated into hourly means and used, along with hourly temperatures from the weather station, to calculate botrytis bunch rot IPs according to the Broome model (Broome et al. 1995) and the Bacchus model (Agnew et al. 2004). The Broome risk categories Low, Moderate and Severe were converted to numerical values 1,2 and 3 respectively. Broome disease risk from individual IPs and the accumulated risk for the whole season for both models were calculated using HortPlus ${ }^{\mathrm{TM}}$ MetWatch software.

\section{RESULTS}

Preliminary analyses showed there was no systematic variation in wetness duration, nor relative differences between inside and outside sensors attributable to different months. Regression analysis showed that the significant independent variables were average hours wetness outside the canopy, and the interaction between average hours wetness outside the canopy and the rainy day indicator $\left(\mathrm{P}<0.001 ; \mathrm{R}^{2}=69.7 \%\right)$. From this analysis two regression equations were derived which described the relationship between wetness inside the canopy and wetness outside the canopy:

$$
\begin{aligned}
& y=2.61+0.55 x \text { for non-rainy days } \\
& y=-1.49+0.94 x \text { for rainy days }
\end{aligned}
$$

where $y=$ hours of wetness inside the canopy and $x=$ hours of wetness outside the canopy, averaged over the respective 10 sensors. For non-rainy and rainy days the intercepts were significantly different from zero $(\mathrm{P}=0.002$ and 0.009 respectively) and the slopes were significantly different from $1.0(\mathrm{P}<0.001$ for both slopes).

The variance of the number of hours wet per day inside the canopy was not significantly different to that outside the canopy, for the overall data, for the individual months and for the categories of rainy and non-rainy days (Table 1 ). Thus the variability in wetness duration over all wet periods measured by sensors inside the canopy appeared similar to that outside the canopy.

Accumulated seasonal disease risk for both Broome and Bacchus models was higher (70 and 90 units respectively) when calculated from sensors outside the canopy than when calculated from sensors inside the canopy (44 and 77 units respectively), reflecting the shorter wetness durations encountered inside the canopy. 
TABLE 1: Degrees of freedom, estimates of variance and F-ratios for various comparisons of the number of hours wet per day inside and outside a grape canopy.

\begin{tabular}{lcccccc}
\hline & \multicolumn{2}{c}{ Degrees of freedom } & & \multicolumn{2}{c}{ Estimate of variance } & \\
\cline { 2 - 3 } Comparison & Inside & Outside & & Inside & Outside & Ratio $^{1}$ \\
\hline Overall & 94 & 107 & & 21.62 & 29.21 & $0.74 \mathrm{~ns}$ \\
Rainy days & 36 & 41 & & 28.57 & 27.75 & $1.03 \mathrm{~ns}$ \\
Non-rainy days & 57 & 65 & & 11.40 & 20.57 & $0.55 \mathrm{~ns}$ \\
December 2002 & 17 & 17 & & 24.79 & 39.79 & $0.62 \mathrm{~ns}$ \\
January 2003 & 17 & 30 & & 22.68 & 36.04 & $0.63 \mathrm{~ns}$ \\
February 2003 & 27 & 27 & & 15.13 & 10.89 & $1.39 \mathrm{~ns}$ \\
March 2003 & 30 & 30 & & 21.33 & 17.62 & $1.21 \mathrm{~ns}$ \\
\hline
\end{tabular}

${ }^{1}$ ns $=$ not significant $\mathrm{P}>0.10$

When moderate and severe Broome IPs from individual sensors were examined, relatively few IPs were common to all sensors. IPs based on wet intervals resulting from substantial rain events were more consistent than IPs resulting from dew. The seven IPs accompanied by more than $10 \mathrm{~mm}$ rain were common to all sensors outside the canopy. All sensors within the canopy detected the same seven IPs, and there was one additional severe IP recorded by a single canopy sensor. However, when IPs occurring solely from dew were considered, the 14 IPs recorded outside the canopy and the 15 recorded inside the canopy were individually detected by fewer sensors (Table 2). Dew based infection periods detected inside the canopy were so inconsistent that no single IP was detected by a majority of the 10 sensors. Only six IPs were common to inside and outside sensors.

TABLE 2: Combined numbers of moderate and severe Broome botrytis bunch rot IPs detected by sensors outside and inside the canopy for non-rainy days.

\begin{tabular}{lcc}
\hline Detected by & Outside & Inside \\
\hline 1 or 2 sensors & 6 & 12 \\
$3-8$ sensors & 4 & 3 \\
9 or 10 sensors & 4 & 0 \\
Total & 14 & 15 \\
\hline
\end{tabular}

\section{DISCUSSION}

For rainy days (equation 3) wetness duration inside the canopy averaged about 1.5 hours less than outside the canopy (significant negative intercept). This reflects a tendency for the canopy to shelter the sensors (and grape bunches) from rain. As well as this offset, wetness duration inside the canopy increased at a slightly smaller rate than outside (slope of 0.94 which was significantly different from 1.0). For days with no rain, i.e. wetness from dew (equation 2), the inside sensors tended to detect some wetness when the outside sensors were dry (significant positive intercept of 2.61). In addition, as wetness duration outside increased, wetness duration inside increased at a much slower rate (slope of 0.55 ). Thus, there were usually shorter wetness durations inside the canopy than outside, although different mechanisms were probably operating for rainy days compared to non-rainy days.

The greater wetness durations for outside sensors were reflected in the higher seasonal risk calculated by both disease models for outside sensors compared to inside sensors. The use of sensors outside the canopy for regional disease risk assessment would therefore give a "worst-case" estimate of risk. However, regression equations would allow an improved estimate of inside-canopy disease risk. The variability of wet periods, in terms 
of hours wet per day, was similar inside and outside the canopy. However, it was clear from the analysis of individual infection periods that there was increased spatial variability when infection periods were monitored inside the canopy compared to outside.

Similar findings on variability within canopies were reported by Penrose \& Nicol (1996). They recorded surface wetness at four locations in apple canopies at seven sites in New South Wales, Australia. Sensor outputs were compared every six hours. On only $10 \%$ of occasions were all four sensors in a tree wet at the same time. When four sensors were placed side by side in the open, they registered the same on $92 \%$ of occasions, so the variability observed in the apple canopy was not primarily due to the sensors. The authors recommended using three sensors within a canopy in any disease warning system. Magarey et al. (2005) similarly found that the uncertainty (95\% confidence limit) for painted flat plate sensors increased from $2 \mathrm{~h}$ in the open to $5 \mathrm{~h}$ in a grape canopy. These authors also discussed multiple sensors, and included a graph showing the reduction in uncertainty as the number of sensors increased.

New unpainted sensors were used in this study, whereas many workers recommend painting with a latex paint in order to spread surface water uniformly and to more closely match the radiative response of a leaf. Painting has its greatest effect in reducing variability during the wetting phase on dew nights (Lau et al. 2000). However there is no standard for the composition and colour of the paint used, and there is a risk of painted sensors responding to high humidity rather than free surface water (Magarey et al. 2005).

\section{ACKNOWLEDGEMENTS}

We thank Peter Wright and Mohan Jeram, Crop \& Food Research, Pukekohe, for maintaining the grape block, and the New Zealand Foundation for Research, Science and Technology for funding.

\section{REFERENCES}

Agnew RH, Mundy DC, Balasubramaniam R 2004. Effects of spraying strategies based on monitored disease risk on grape disease control and fungicide usage in Marlborough. New Zealand Plant Protection 57: 30-36.

Broome JC, English JT, Marois JJ, Latorre BA, Aviles JC 1995. Documentation of an infection model for botrytis bunch rot of grapes based on wetness duration and temperature. Phytopathology 85: 97-102.

Gillespie TJ, Kidd GE 1978. Sensing duration of leaf moisture retention using electrical impedance grids. Canadian Journal of Plant Science 58: 179-187.

Henshall WR, Beresford RM, Chynoweth RW 2003. Does variability in grape canopy wetness affect infection period calculations? $8^{\text {th }}$ International Congress of Plant Pathology, Christchurch, New Zealand. Volume 2 (Abstracts of offered papers): 110.

Hortplus $^{\mathrm{TM}}$ undated. Products. http://www.hortplus.com [accessed 7 April 2005].

Lau YF, Gleason ML, Zriba N, Taylor SE, Hinz PN 2000. Effects of coating, deployment angle, and compass orientation on performance of electronic wetness sensors during dew periods. Plant Disease 84: 192-197.

Magarey RD, Weiss A, Gillespie TJ, Huber L, Seem RC 2005. Estimating surface wetness duration in plants. In: Hatfield JL ed. Micrometeorological measurements in Agricultural systems. American Society of Agronomy (in press).

Penrose LJ, Nicol HI 1996. Aspects of microclimate variation within apple tree canopies and between sites in relation to potential Venturia inaequalis infection. New Zealand Journal of Crop and Horticultural Science 24: 259-266. 